UCRL-CR-141282

B505002

\title{
Research on Parallel Adaptive Finite Element Methods
}

M. Holst

November 6, 2000

U.S. Department of Energy

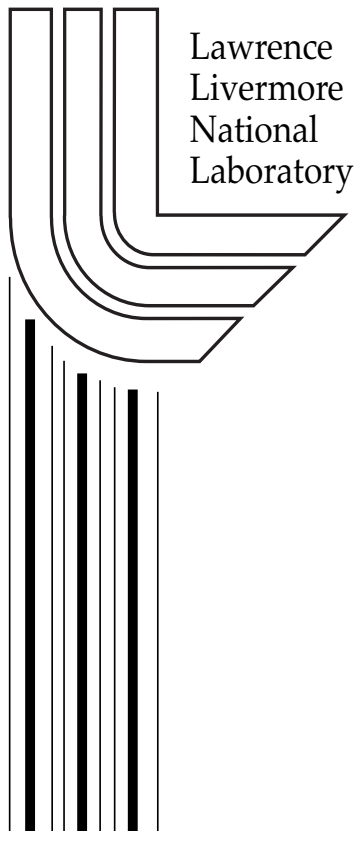




\section{DISCLAIMER}

This document was prepared as an account of work sponsored by an agency of the United States Government. Neither the United States Government nor the University of California nor any of their employees, makes any warranty, express or implied, or assumes any legal liability or responsibility for the accuracy, completeness, or usefulness of any information, apparatus, product, or process disclosed, or represents that its use would not infringe privately owned rights. Reference herein to any specific commercial product, process, or service by trade name, trademark, manufacturer, or otherwise, does not necessarily constitute or imply its endorsement, recommendation, or favoring by the United States Government or the University of California. The views and opinions of authors expressed herein do not necessarily state or reflect those of the United States Government or the University of California, and shall not be used for advertising or product endorsement purposes.

Work performed under the auspices of the U. S. Department of Energy by the University of California Lawrence Livermore National Laboratory under Contract W-7405-Eng-48. 
UCRL-CR-121282

University of California, San Diego

La Jolla, CA

\section{Research on Parallel Adaptive Finite Element Methods}

Submitted by:

Michael Holst

FINAL REPORT

For the period ending July 9, 1999

Prepared for:

University of California

Lawrence Livermore National Laboratory

Attn: Jill Dunaway

P.O. Box 808, L-561

Livermore, CA 94551

Under

B505002 


\title{
FINAL REPORT .LLNL Visit in Summer 1999
}

\author{
Michael Hoist \\ UCSD Department of Mathematics
}

\section{Research on Parallel Adaptive Finite Element Methods}

In this project we studied several fundamental issues arising in the parallel adaptive solution of linear and nonlinear elliptic and parabolic PDEs using multilevel algorithms. We focused our attention on a new approach described in the paper "A New Paradigm for Parallel Adaptive Mesh Refinement" by Bank and Hoist. The new approach requires almost no communication to solve an elliptic equation in parallel, and therefore has the potential to scale much more efficiently on massively parallel computers than do more traditional algorithms. The algorithm described in the Bank and Hoist paper has an inherently multilevel structure, in that a sequence of problems on a refinement hierarchy of meshes is solved during the course of the calculation. In particular, the algorithm has three main components:

- We solve a small problem on a coarse mesh, and use a posteriori error estimates to partition the mesh.

- Each processor is provided the complete coarse mesh and instructed to solve the entire problem, but with its adaptive refinement largely limited to its own assigned mesh partition.

- A final mesh is computed using the union of the refined partitions provided by each processor. The mesh is regularized into a global conformal mesh, and a final solution is computed using a standard overlapping domain decomposition method or a parallel multigrid method.

In certain circumstances the third step can be avoided, leading to an algorithm with no communication beyond that required to synchronize the processors at the beginning of the calculation.

We looked at the algorithm closely during the LLNL project in Summer 1999, and we examined algorithms for performing the third step of the algorithm efficiently on massively parallel computers, including parallel multilevel methods and mortar element methods. One result of the summer work at LLNL was a scheme for producing a global conforming mesh in the $3 \mathrm{D}$ case through the use of a consistent tie-breaking approach in conjunction with longest-edge simplex bisection. This result completely removes some of the implementation complexity that normally makes the $3 \mathrm{D}$ case much more difficult that the 2D case.

We presented our work on the parallel algorithm at the Workshop on Iterative Methods held in Livermore in Summer 1999. 